\title{
Perspektif Jurnalis Media Konvergen Terhadap Berita Keberagaman
}

\author{
Moehammad Gafar Yoedtadi $^{1}$, Lusia Savitri ${ }^{2}$ \\ ${ }^{1}$ Fakultas Ilmu Komunikasi, Universitas Tarumanagara, Jl. S. Parman No.1, Jakarta, 11440 \\ E-mail: gafary@fikom.untar.ac.id \\ ${ }^{2}$ Fakultas Ilmu Komunikasi, Universitas Tarumanagara, Jl. S. Parman No.1, Jakarta, 11440 \\ E-mail: lusias@fikom.untar.ac.id
}

\begin{abstract}
Isu keberagaman merupakan isu sensitif yang jika tidak ditangani dengan bijaksana akan menjadi persoalan yang mendegradasi kerukunan bangsa. Media massa yang memiliki fungsi-fungsi ideal sebagai medium informasi dan sosialisasi, dirasa masih kurang memberi perhatian terhadap isu keberagaman. Padahal peran media massa, terutama media massa konvergen sangat berpengaruh terhadap hal ini. Penelitian ini dilakukan dengan tujuan untuk mendapatkan gambaran pandangan para jurnalis dari media konvergen Liputan 6.com dalam melihat isu keberagaman. Jurnalis yang menjadi partisipan adalah dari level senior (wakil pemimpin redaksi), madya (redaktur), dan yunior (reporter). Metode penelitian menggunakan kualitatif dengan pendekatan fenomenologi. Dasar teori yang digunakan dalam penelitian ini adalah jurnalisme damai dan pengaturan agenda media. Penggalian data dilakukan dengan wawancara mendalam dan juga observasi. Hasil penelitian menunjukkan bahwa kebijakan redaksi Liputan 6.com untuk berhati-hati dalam memberitakan topik keberagaman (unsur SARA) telah dipahami secara seragam oleh tiap level jurnalis. Selain itu ada kesadaran yang dimiliki secara pribadi dari tiap partisipan untuk mengedepankan kehati-hatian dalam memberitakan tipik keberagamany.
\end{abstract}

Keywords —: isu keberagaman; perspektif jurnalis; media konvergen.

\section{PENDAHULUAN}

Isu keberagaman merupakan persoalan penting untuk dikaji. Kondisi masyarakat Indonesia yang multikultur membutuhkan situasi yang kondusif agar terjadi harmoni dalam kehidupan bersama. Karena kemajemukan dalam banyak hal - suku, ras, agama, golongan, seharusnya menjadi khazanah atau modal untuk membangun masyarakat yang maju, namun sering kali dijadikan alat pemecah belah (Liliweri, 2009). Media massa memegang peran penting dalam menyebarkan pemahaman nilainilai keberagaman. McQuail (2011) memaparkan empat fungsi media massa di masyarakat, yakni sebagai medium pengawasan, sosialisasi, transformasi dan hiburan. Media masa dapat menjadi medium untuk sosialisasi nilai-nilai keberagaman. Namun, media massa kurang memberikan perhatian terhadap isu keberagaman (Loisa, Susanto, Junaidi, Loekman, 2019).

Keengganan media massa memberikan porsi pemberitaan terhadap peristiwa atau permasalahan seputar isu keberagaman boleh jadi memiliki dua alasan, pertama isu keberagaman kurang menarik dari sisi komersial, kedua, isu keberagaman mengandung risiko menimbulkan kericuhan di masyarakat. Berdasarkan penelitian Loisa, Susanto, Junaidi, Loekman (2019) mengenai isu keberagaman dalam pemberitaan media siber menunjukkan, kurangnya indepedensi media dalam memberitakan isu keberagaman dengan lebih banyak mengutip narasumber utama dari sisi aparat pemerintah untuk menghidari risiko menimbulkan kericuhan.

Padahal peran media massa sangat ditunggu sebagai otoritas kebenaran faktual dan institusi verifikasi resmi terhadap berbagai informasi yang kini sangat berlimpah. Situasi pasca reformasi memberi kebebasan dalam praktik bermedia dan menyebabkan jumlah media yang lahir meningkat tajam. Namun penambahan jumlah media ternyata tidak disertai kemampuan bermedia yang baik. Pelanggaran regulasi dan etika oleh media kerap terjadi. Pada 2018 Dewan Pers menerima 600 surat pengaduan dari masyarakat terhadap media massa. Jumlah tersebut tergolong tinggi dibandingkan negara-negara ASEAN yang hanya 20 pengaduan per tahun (Tempo.co, 2018). Jumlah pengaduan yang meningkat bisa jadi didorong juga oleh perubahan sistem politik pasca reformasi yang memberikan otonomi daerah dan desentralisasi kekuasaan. Hal itu mendorong lahirnya semangat kedaerahan, etnis dan ekspresi keagamaan yang tinggi di daerah yang tercermin dari meningkatnya ekspresi-ekspresi bersifat SARA oleh media-media lokal (Junaidi, 2017).

Persoalan media nir-etika tadi masih ditambah dengan kian mudahnya masyarakat untuk memiliki medianya sendiri. Dengan teknologi internet 2.0, masyarakat dapat berperan sebagai produsen media dengan memanfaatkan media sosial. Siapapun dapat menjadi produsen konten atau disebut sebagai user generated content (Hartanti, 2018). Sementara di media sosial tak semua orang paham regulasi dan etika, serta menyadari bahayanya memproduksi konten-konten yang negatif, seperti menyebarkan rasa permusuhan, ujaran kebencian, prasangka SARA dan fitnah (hoax). Berdasarkan survei yang dilakukan Masyarakat Telematika Indonesia (Mastel) pada 7-9 Februari 2017 terhadap 1.116 responden di Indonesia, sebanyak 44,33 persen masyarakat menyatakan menerima berita hoaks setiap hari dan 17,2 persen menerima lebih dari satu kali (Juditha, 2018). Sepanjang tahun 2016 Direktorat Reskrimsus Polda Metro Jaya memblokir 300 lebih akun media sosial dan media online yang 
menyebarkan konten hoax, provokasi dan SARA, serta 800 ribu akun terindikasi sebagai penyebar berita palsu dan ujaran kebencian (Septanto, 2018).

Menilik situasi di atas, sejatinya media diharapkan menjadi rujukan masyarakat untuk mendapatkan informasi yang benar, terutama pada isu keberagaman. Lantas bagaimanakan pandangan awak redaksi media terhadap isu keberagaman? Penelitian ini hendak menjawab pertanyaan tersebut dengan memilih objek penelitian pada sebuah media terkenal, yakni Liputan6.com. Liputan 6.com adalah media hasil konvergensi antara televisi dan media online. Dengan demikian produksi konten pada media tersebut merupakan konten multi platform. Menurut situs pemeringkat media online Alexa.com, Liputan6.com adalah media yang paling banyak dikunjungi oleh pengguna internet selama 2017.

Sebelum penelitian ini, telah ada beberapa penelitian yang mengupas mengenai media dan isu keberagaman. Pertama adalah penelitian berjudul "Media Siber, Aparat dan Pemberitaan Keberagaman". Penelitian ini mengungkap relasi jurnalis dan aparat pemerintah yang demikian erat dalam memberitakan kasus keberagaman. Oleh media siber aparat pemerintah merupakan narasumber utama dalam pemberitaan keberagaman. Dinamika relasi media dan aparat pemerintah dalam pemberitaan isu keberagaman pada masa lalu lebih didasarkan pada kekuasaan, sementara kini disebabkan alasan kepentingan mendesak,akurasi dan pengelolaan resiko (Loisa, Susanto, Junaidi, Loekman, 2019).

Penelitian mengenai media dan isu keberagaman lainnya adalah "Media dan Keberagaman: Analisis Pemberitaan Media Daring Seputar Pemilihan Kepala Daerah DKI Jakarta". Penelitian ini berfokus pada isi pemberitaan seputar pemilihan Gubernur DKI Jakarta pada masa kampanye 26 Oktober 2016 sampai dengan 11 Februari 2017 di sepuluh media daring. Hasil penelitian menunjukkan penggunaan isu agama dan posisi politik pemilik media berpengaruh terhadap isi berita (Junaidi, 2018).

Penelitian lainnya terkait media dan isu keberagaman adalah "Peran Media dalam Menyatukan Perbedaan di Indonesia: Analisis Wacana Terhadap Isu Perayaan Hari Besar Keagamaan di Media.” Hasil penelitian ini menyimpulkan Kompas.com dan Republika.com mencoba membangun wacana tertentu terkait perayaan hari besar keagamaan. Kompas.com membangun wacana bahwa perayaan hari raya Idul Fitri tahun 2016 diwarnai rentetan aksi teror bom bunuh diri. Sementara Republika.com membingkai perayaan Natal sebagai suatu perayaan yang rentan akan aksi anarkis sehingga membutuhkan pengamanan personil keamanan (Limilla, 2016).

Dari penelitian-penelitian sebelumnya, dapat dikatakan penelitian kali ini memiliki kemajuan karena memilih media siber yang merupakan media hasil konvergensi televisi dan internet yakni Liputan6.com. Media yang diteliti memiliki konten multi platform. Selain itu penelitian ini berupaya menggali perspektif para awak redaksi di level senior, madya dan yunior di Liputan6.com mengenai isu keberagaman. Dengan demikian tidak hanya pandangan dan pengalaman para jurnalis menganai isu keberagaman yang akan tergali oleh penelitian ini, tapi juga dari sisi kebijakan redaksi baik yang tertulis maupun tak tertulis.

\section{METODE PENELITIAN}

Penelitian ini menggunakan pendekatan kualitatif dengan metode fenomenologi. Pendekatan kualitatif menurut Bogdan dan Taylor (Moleong, 2000) merupakan prosedur penelitian yang menghasilkan data deskriptif berupa kata-kata tertulis atau lisan dari orang-orang dan perilaku yang dapat diamati. Sementara metode fenomenologi, menurut Creswell (2007) digunakan peneliti untuk mencari pengalaman-pengalaman pelaku dalam menghadapi lingkungannya. Husserl dan Merleau-Ponty (dalam Kuswarno, 2009) menjelaskan bahwa fenomenologi digunakan peneliti untuk mengungkap tipe-tipe pengalaman, dalam bentuk deskripsi, dimasa lalu. Studi fenomenologi menggambarkan makna dari beberapa individu mengenai pengalaman hidup mereka atas suatu konsep atau sebuah fenomena (Creswell, 2007). Fenomenologi dalam penelitian ini digunakan untuk mendapatkan perspektif para awak redaksi Liputan 6.com dalam memandang isu keberagaman dan aplikasinya dalam kerja redaksi. Penelitian akan melibatkan tiga level jurnalis dalam struktur redaksi, yakni level senior, madya, dan yunior. Dengan fenomenologi diharapkan dapat mengungkap pengalaman-pengalaman, latar belakang tindakan para jurnalis, serta kebijakan redaksi ketika memproduksi berita isu keberagaman. Subjek penelitian ini adalah Wakil Pemimpin Redaksi Liputan 6. com Elin Yunita Kristanti, Redaktur Liputan 6. com Mohamad Nurfahmi Budiarto, Reporter Liputan 6.com Ika Defianti. Objek penelitian ini adalah pengalaman dan pendapat para jurnalis Liputan 6.com dalam memberitakan isu-isu keberagaman.

Analisa data akan dilakukan dengan reduksi data, penyajian data serta penarikan kesimpulan dan verifikasi. Sebagaimana dikatakan oleh Miles dan Huberman (1984) bahwa aktivitas dalam analisis data kualitatif dilakukan secara interaktif dan berlangsung secara terus menerus sampai tuntas, sehingga datanya jenuh. Ukuran kejenuhan data ditandai dengan tidak diperolehnya lagi data atau informasi baru.

\section{III.HASIL DAN PEMBAHASAN}

\section{A. Profil Liputan6.com}

Liputan6.com merupakan portal berita yang terdaftar dan telah diverifikasi di Dewan Pers. Liputan6.com berdiri sejak Agustus 2000. Pada awalnya Liputan6.com hanya menyajikan berita yang sudah tayang di stasiun televisi pada acara berita Liputan6 SCTV (Surya Citra Televisi). Dengan kata lain Liputan6.com dimiliki dan dioperasikan oleh stasiun televisi SCTV, dan merupakan media konvergen televisi dan internet. Sejak 24 Mei 2012, induk perusahaan SCTV, PT Elang Mahkota Teknologi Tbk (Emtek), yang merupakan perusahaan terbuka dan tercatat di Bursa Efek Indonesia, memutuskan untuk memisahkan Liputan6.com dari SCTV dengan mendirikan perusahaan sendiri, PT Kreatif Media Karya (KMK). PT KMK 
merupakan anak perusahaan Emtek. Saham PT KMK sebanyak 99,99 persen dimiliki oleh PT Elang Mahkota Teknologi Tbk (Emtek).

Dalam perjalannya lahir peraturan baru yang dikeluarkan oleh Dewan Pers, bahwa setiap perusahaan pers harus memiliki badan hukum sendiri. Untuk itu sejak 14 Maret 2016 portal Liputan6.com dilepaskan dari PT KMK, kemudian dimiliki dan dioperasikan sendiri oleh PT Liputan Enam Dot Com, yang menjadi anak perusahaan PT KMK dengan kepemilikan saham 99,99 persen.

Pada Februari 2018, terjadi aksi penggabungan dua perusahaan dalam rangka membentuk sinergi. PT KMK melakukan akuisisi kepemilikan PT Kapan Lagi Network (KLN). PT KLN adalah induk dari sejumlah media online antara lain Merdeka.com, Bola.net, Vemale.com, Fimela.com, Brilio.net, Famous.id dan Dream.co.id. Hasil akuisisu tersebut adalah PT KMK menjadi pemegang saham terbesar PT KLN, yakni menguasai 50 persen plus 1.saham KLN. Akuisisi saham ini dibarengi dengan sinergi unit usaha bisnis digital dan perubahan susunan pemegang saham PT KLN dan PT Liputan Enam Dot Com, anak usaha PT KMK yang membawahi Liputan6.com, Bintang.com, dan Bola.com. KLN akan memiliki dan memegang 99,9 persen saham di PT Liputan Enam Dot Com (Tirto, 2018). Per Maret 2018, operasional PT Liputan Enam Dot Com ada di bawah PT Kapan Lagi Dot Com Networks yang menguasai 99,99\% saham.

Pada perkembangan lebih lanjut, PT Kapan Lagi Dot Com Networks diambil alih dan dimasukkan sebagai anak perusahaan PT Surya Citra Media (SCM). SCM adalah perusahaan yang menyediakan layanan multimedia. Perusahaan ini adalah induk dari stasiun televisi SCTV, Indosiar Visual Mandiri, O Channel dan Vidio.com. PT SCM merupakan anak usaha dari PT Emtek Tbk. Keberadaan Liputan6.com di bawah PT SCM dapat disebut sebagai bagian dari strategi konvergensi media.

\section{B. Peran Media dalam Konteks Keberagaman}

Sikap redaksi Liputan6.com sejak awal lebih mengedepankan konsep keberagaman. Redaksi Liputan6.com menyadari realitas keanekaragaman pada masyarakat Indonesia. Menurut narasumber penelitian, wakil pemimpin redaksi Liputan6.com Elin Yunita Kristanti, heterogenitas masyarakat Indonesia, baik dari sisi kultur, agama dan etnis merupakan kelebihan yang dimiliki oleh bangsa Indonesia. Heterogenitas menjadi modal pengikat persatuan. Namun, hal itu juga menjadi kekurangan manakala pelbagai keragaman tersebut justru dimanfaatkan oleh masyarakat untuk memecah belah persatuan. Disinilah, menurut Elin, peran media massa diharapkan hadir sebagai medium pencerahan dan penyadaran terhadap masyarakat mengenai realitas keberagaman pada masyarakat Indonesia. Sebagaimana halnya yang disampaikan McQuail (2011) bahwa media harus bertindak sebagai panggung untuk kepentingan-kepentingan dan sudut pandang yang berbeda di dalam masyarakat atau komunitas.

Aplikasi di tingkat produksi berita di Liputan6.com adalah dengan senantiasa memberikan ruang terhadap perbedaan. Dalam memberitakan suatu kasus konflik antar aliran agama, misalnya, sudut pandang pemberitaan (angle) yang dipilih tidak serta merta menggunakan kaca mata kelompok mayoritas, tetapi memberi ruang untuk kelompok minoritas. Hal itu dilakukan agar keberimbangan dalam pemberitaan (balance) dapat dihadirkan, karena suara kelompok minoritas dapat ditampilkan. Media, menurut Erlin, tidak hanya berfungsi menjadi penyampai informasi, tapi juga menjalankan peran literasi mengenai keberagaman kepada masyarakat. Berikut pernyataan dua narasumber penelitian Elin Yunita Kristanti dan Mohamad Nurfahmi Budiyanto:

"Saya sangat yakin media massa tidak hanya menyampaikan informasi, tapi lebih dari itu media massa harus bisa mencerahkan, itu persepsi saya sebagai wartawan ya, media massa juga menjadi salah satu bagian dari upaya literasi terhadap masyarakat, ada banyak kasus dimana masyarakat berangkat dari ketidaktahuan, atau hanya berdasarkan katanyakatanya padahal belum dibuktikan kebenarannya, jadi kita juga harus membuka ruang dialog. Saat ini ada anggapan kecenderungan populisme, yang mayoritas merasa terancam oleh yang minoritas, ini berbahaya karena minoritas tidak mempunyai ruang bicara”. (Wakil Pemimpin Redaksi Liputan6.com Elin Yunita Kristanti)

"Kalau orang yang gak punya literasi media yang bagus kan akhirnya kayak kacamata kuda. Misal dia terlalu fanatik sama Republika, terlalu fanatik sama Kompas, fanatik sama Bisnis Indonesia misalnya, dia terlalu fanatik sama Wartakota misalnya, udah dijadiin kayak agama, itu yang berbahaya. Dan tugas media harusnya jangan malah terlena, oh aku punya pembaca yang kayak gini, tetapi bagaimana cara kita memanfaatkan ketika kita punya pembaca yang fanatik tapi kita memasukkan unsurunsur yang benar-benar edukasional, mendidik gitu. Itu sih challenge nya. Media bisa menjadi salah satu corong penghancur keberagaman sih, bisa menghancurkan demokrasi, satu pilar, tiga pilarnya hancur misalnya kan gara-gara media." (Redaktur Liputan6.com Mohamad Nurfahmi Budiyanto)

Sikap redaksi Liputan6.com dalam memberitakan kasus-kasus keberagaman dengan memberi kesempatan kelompok minoritas sesuai dengan pemikiran McQuail (2011) bahwa media harus menawarkan kesempatan yang kurang lebih sama kepada suara dari beragam minoritas sosial budaya yang menjadi bagian dari masyarakat.

Peran literasi keberagaman dijalankan Liputan6.com antara lain dengan memproduksi berita-berita bertema kerukunan antar etnik atau antar agama. Sebagai contoh berita tentang peristiwa saling bantu-membantu antar umat beragama, antara umat Muslim dan umat non-Muslim. Pada bulan Ramadan umat non-Muslim ikut menyiapkan hidangan berbuka puasa atau takjil untuk umat Muslim. Sementara pada perayaan Natal umat Muslim ikut menjaga pengamanan gereja. 
Website : http://sosial.unmermadiun.ac.id/index.php/sosial

\section{Kebijakan Redaksi Berita Keberagaman}

Redaksi Liputan6.com menyadari potensi kerawanan dari pemberitaan keberagaman khususnya konflik SARA. Menurut Elin, berita semacam itu dapat memperluas eskalasi konflik dan mengundang permusuhan di atara pihak-pihak yang sesungguhnya tidak terlibat. Media harus memikirkan dampak Berita yang mengandung pertentangan antar agama, etnis dan budaya dapat Berikut pernyataan Elin Yunita Kristanti, Wakil Pemimpin Redaksi Liputan6.com:

"Ada baiknya media massa itu mengerem ya, ketika kita membuat berita itu juga memikirkan impack dari apa yang kita beritakan artinya untuk isu-isu tertentu soal keberagaman dan SARA kita harus mengeremlah, kita harus sadarlah apapun yang kita keluarkan itu bisa membuat impact di masyarakat dan bisa membuat makin lebar". (Wakil Pemimpin Redaksi Liputan6.com Elin Yunita Kristanti)

Sikap "mengerem" dalam memberitakan kasus yang rawan konflik SARA sebagaimana diungkapkan oleh Elin, adalah berhati-hati dalam penulisan pemberitaan. Seperti yang dicontohkan oleh redaktur Liputan6.com Mohamad Nurfahmi Budiyanto pada pemberitaan kasus seorang wanita membawa anjing ke dalam masjid. Fakta yang diperoleh di lapangan tidak bisa serta merta ditulis sesuai kenyataan di lapangan. Ada beberapa bagian fakta yang tidak diungkapkan dalam narasi berita karena berpotensi mengundang kebencian antar agama. Redaksi Liputan6.com harus mengemasnya dengan baik agar tidak terjadi kehebohan di masyarakat. Sebagaimana dikatakan Wallace (2018) bahwa fungsi gatekeeping berupa menyeleksi, menulis, menyunting informasi menjadi berita dilakukan dengan mengikuti kebijakan redaksi. Berikut pernyataan redaktur Liputan6.com Mohamad Nurfahmi Budiyanto:

"Ya tadi kalau fakta itu nggak apa-apa, dia mencari suaminya, dia bawa anjing, mencari suaminya, ditanyain sama takmir situ. Dia nanya atau enggak ditanyain gitu karena disitu sesuai dengan videonya. Ya udah dideskripsikan aja tetapi tanpa menyebut dia Kristen, tanpa menyebut membawa anjing ke masjid itu haram, misalnya. Fakta itu biasanya lanjutannya, biasanya fakta yang realnya itu dia bawa anjing ke masjid, kemudian ketemu terus udah, titik, selesai. Tanpa seharusnya "oh seharusnya dia najis". Nah kalau media media yang terlalu click-bait mereka mengarahkan ke najis itu. tetapi kalau saya di Liputan Enam, ya enggak. Ya selesai bahwa ada fakta itu tanpa kita harus ngomong ke MUI untuk pinjam mulutnya kalau itu haram, enggakjuga”. (Redaktur Liputan6.com Mohamad Nurfahmi Budiyanto)

Sebagian besar wartawan Liputan6.com memahami kebijakan redaksi tersebut. Menyadari posisi media tempat mereka bekerja memiliki kebijakan redaksi yang berbeda dengan media daring yang lain, khususnya dalam memberitakan isu keberagaman. Media-media daring lain cenderung membuat berita yang sensasional untuk menghasilkan click bait. Clickbait menurut Hurst (2016) adalah suatu taktik membuat berita bersifat sensasional dan dirancang untuk menarik perhatian dan membujuk rasa ingin tahu khalayak tentang cerita yang mereka rujuk tanpa mengungkapkan informasi kunci. Reporter Liputan6.com diminta berhati-hati ketika melakukan liputan yang berhubungan dengan kasus keberagaman. Mereka menghindari provokasi dan sensasi. Berikut pernyataan Ika Yustiana reporter Liputan6.com:

'Kami sadar kami berbeda dengan portal berita lain seperti 'detik' atau 'tribun' yang bisa dengan bebas meliput beritaberita yang mengandung unsur perdebatan SARA. Kalau dengan detik dan tribun saya suka bilang kamu enak bisa nulis yang begini dengan bebas, kalau saya harus hati-hati. Jangan sampai memprovokasi orang. Selain itu kami juga dialog dengan redaktur lebih dulu apakah sebuah peristiwa tertentu dapat diliput atau tidak. Biasanya redaktur atau mbak Elin yang sering mengingatkan untuk menghindari peliputan tersebut atau nulisnya tidak berat sebelah. (Reporter Liputan6.com Ika Yustiana)

Wallace (2018) mengatakan bahwa gatekeeping terjadi pada dua tahap; saat peliputan (news gathering) yang menemukan dan mengosolidasikan ke dalam berita, dan proses produksi berita (news processing) yang mengubah item berita menjadi produk lengkap yang siap dipublikasikan. Dari pernyataan Mohamad Nurfahmi Budiyanto dan Ika Yustina di atas dapat terlihat bahwa fungsi gatekeeping dijalankan secara hati-hati oleh redaksi Liputan6.com. Kehatian-hatian tersebut terlihat dari gatekeeping yang dilakukan pada dua tahap, yaitu pada peliputan dan penyuntingan berita. Pada peliputan reporter telah menyeleksi terlebih dulu peristiwa yang layak untuk diliput. Ketika peristiwa tersebut berkaitan dengan topik keberagaman dan rawan konflik maka bisa jadi pilihannya adalah tidak diliput. Pada tahap produksi berita, penyuntingan oleh redaktur terjadi proses gatekeeping dengan memilih sudut pandang (angle) dan narasi yang lebih aman.

\section{IV.KESIMPULAN}

Pemahaman anggota redaksi Liputan6.com mengenai keberagaman telah memiliki kesamaan konsep, bahwa masyarakat Indonesia terbagi atas beranekaragam suku, budaya, agama dan tingkat sosial. Karena itu peran media dapat menjadi instrumen pemersatu dan melakukan tugas literasi keberagaman di masyarakat. Fungsi literasi keberagaman dilakukan dengan memberitakan beragam peristiwa yang menunjukkan kerukunan antar agama atau antar etnik. Diharapkan dengan berita-berita tersebut, konsep keberagaman dapat dipahami oleh masyarakat.

Dalam memberitakan kasus keberagaman, Liputan6.com menekankan sikap kehati-hatian agar pemberitaan mereka tidak menimbulkan dampak negatif di masyarakat berupa eskalasi konflik. Pada pemberitaan perbedaan antar suku, agama, dan ras, redaksi Liputan6.com melakukan proses gatekeeping secara ketat dalam pada tahap peliputan (news gathering) dan tahap penyuntingan berita (news processing). 
Website : http://sosial.unmermadiun.ac.id/index.php/sosial

\section{UCAPAN TERIMAKASIH}

Terima kasih kepada Lembaga Penelitian dan Pengabdian Masyarakat Universitas Tarumanagara yang telah mendanai penelitian ini.

\section{VI.DAFTAR PUSTAKA}

Abunales, Daniel. (2016). Peace Journalism: Preparing Aspiring Journalists to Value Culture of Peace. Asia Pasific Media Educator. 26(2): 252-269. DOI: $10.1177 / 1326365 X 16666851$

Juditha, Christiany. (2016). Jurnalisme Damai dalam Berita Konflik Agama Tolikara di Tempo.co. Jurnal Penelitian Komunikasi dan Opini Publik. 20(2): 93110.

Krisdinanto, Nanang. (2014). Anomali dan Teori Hirarki Pengaruh Terhadap Isi Media. Komunikatif Jurnal Ilmiah Komunikasi. 3(1): 1-18

Kovach, Bill; Rosenstiel, Tom. (2001). Sembilan Elemen Jurnalisme. Pantau: Jakarta.

Lindawati, Debora Sanur. (2011). Konflik Ambon: Kajian Terhadap Beberapa Akar Permasalahan dan Solusinya. Politica. 2(2): 271-297.

Lynch, J., McGoldrick, A. (2012). Responses to Peace Journalism. Journalism: theory, practice \& criticsm. 14(8): 1041-1058. DOI: $10.1177 / 1464884912464175$

Loisa, Riris; Susanto, Eko Hary; Junaidi, Ahmad; Loekman, Felicia. (2019). Media Siber, Aparat dan Pemberitaan Keberagaman. Jurnal ASPIKOM. 3(6) $1243-1253$.

Miles, Mathew B; Huberman, A Michael. (1992). Analisis Data Qualitatif. Jakarta: UI Press

Pardede, Anton Pemmilianan. (2007). Meretas Jurnalisme Damai di Aceh. Jakarta: Yayasan Pustaka Obor Indonesia.

Peleg, Samuel. (2006). Peace Journalism Through the Lense of Conflict Theory: Analysis and Practice. Conflict \& Communication Online, 5(2): 1-17.

Qurtuby, Sumanto Al. (2016). Religious Violence and Conciliation in Indonesia Christians and Muslims in the Moluccas. Routledge: London and New York.

Santosa, Bend Abidin. (2017). Peran Media Massa dalam Mencegah Konflik. Jurnal ASPIKOM. 3(2): 199-214.

Shoemaker, Pamela J; Reese, Stephen D. (2013). Mediating the Message in Twenty First Century: A Media Sociology Perspective. New York: Routledge

Sudibyo, Agus. (2013). Politik Media dan Pertarungan Wacana. LKiS: Yogyakarta. 